\title{
MicroscopyPioneers
}

\section{Pioneers in in situ Electron \\ Microscopy: Lawrence (Larry) Allard, Oak Ridge National Laboratory}

\section{Cameron Varano}

The Pennsylvania State University, 201 Old Main, University Park, PA 16802

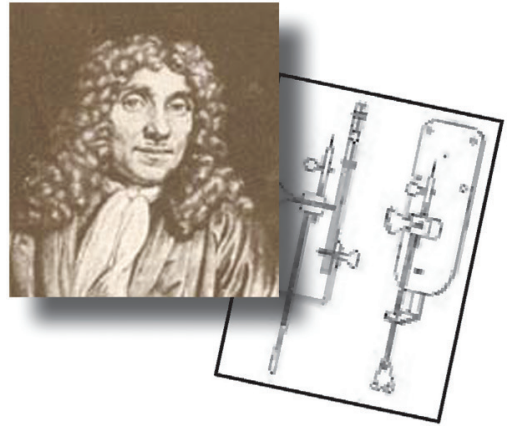

cvarano@psu.edu

\section{Lawrence (Larry) Allard}

(born 1943)

While it is true that the story of Dr. Lawrence (Larry) Allard begins with his birth on October 28, 1943, the first 18 years were unremarkable in regard to microscopy. The story of how he came to be a pioneer in the field of in situ microscopy begins in the summer of 1961, after he graduated high school in Grand Rapids, Minnesota, and moved to

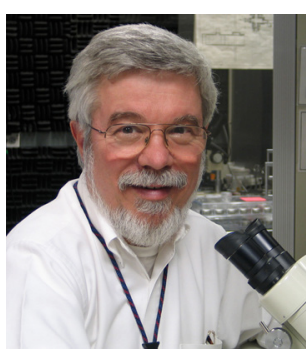

Lawrence (Larry) Allard Detroit. In Detroit, his aim was to live frugally and work long hours in a meat-packing facility to earn enough money for college, which he accomplished in 15 months. His scholastic aptitude also earned him a scholarship to Michigan State University, which would have covered nearly four semesters of tuition. However, his cousin was a graduate of the University of Michigan and intervened to redirect Allard to Michigan where he began in the fall of 1962 .

The money earned at the meat-packing plant should have been enough to get him through most of his undergraduate training. However, it seems that the freshman year of college has a universal effect on young students, and after his first year at the University of Michigan, he was in need of employment. As a freshman in his second semester, he was wandering the halls of a university engineering building and passed a door labeled "Electron Microscope." The phrase piqued his interest, so he entered and found someone sitting in the dark looking into the glowing window of a "wonderful instrument." After promising not to ask questions, he was allowed to watch. The experience bewitched him, although he did not have a clue about any of it. Shortly afterwards, he attended an information session run by Professor Wilbur Bigelow. Each student was asked to write their interests on a card. Allard wrote of one interest: "the electron microscope." This ignited a relationship with Professor Bigelow in the fall of 1963, which continues in collaboration to this day. After proving his interests and wits,
Allard earned a paying position in the Bigelow lab as a research assistant where he was able to earn enough to cover his tuition and discover his passion.

In 1965 Prof. Bigelow and Prof. Lawrence Brockway were collaborating on a new project funded by the Oak Ridge Gaseous Diffusion Plant (ORGDP) to study gas reactions on single crystals of copper, and they wanted to do it using in situ electron microscopy. Brockway and Bigelow built a top-entry heating stage and gas-handling manifold for the JEOL JEM-6A $100 \mathrm{kv}$ electron microscope. Allard was tasked with building the heaters and the daily operation of the microscope. The platform, while rudimentary compared to today's instrumentation, had the capability to heat to $-500^{\circ} \mathrm{C}$, with reaction gas fed directly into the column. The experiments began by annealing single-crystal foils with hydrogen gas. Then hydrogen was exchanged with oxygen at pressures testing the limit of the microscope's vacuum. The oxygen had the inconvenient side effect of burning out the tungsten filament every few days. Yet, it worked, and the formation of copper oxide grains was recorded using a $16 \mathrm{~mm}$ cine

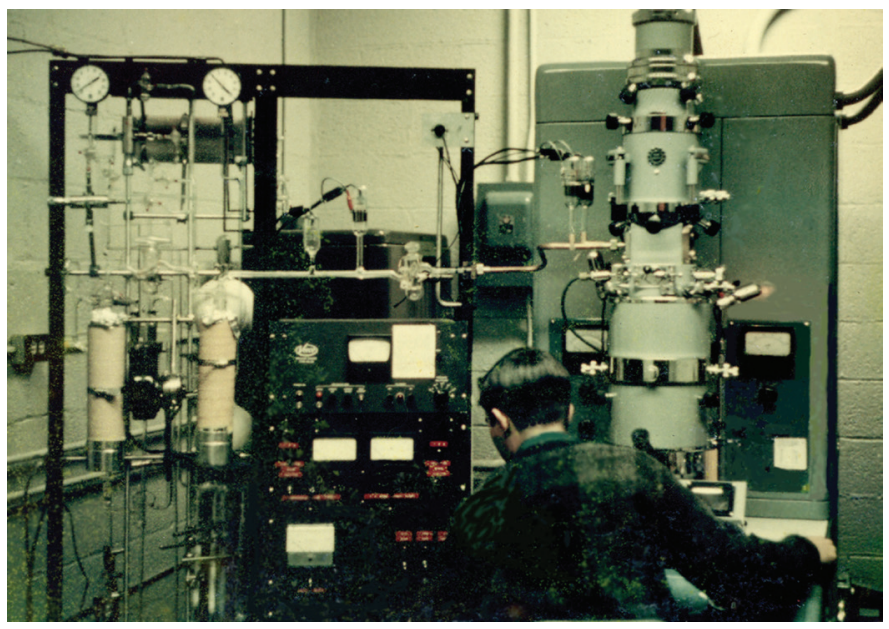

Figure 2: Dr. Larry Allard at the JEOL JEM-6A TEM during the summer of 1965. The gas manifold included hard coupling to the column, gas purification capability, and reasonable pressure measurement with BA and Pirani gauges. 
camera, during the summers from 1965 to 1967 (Figure 2). Dr. Allard still has these movies. He remembers this time as "more fun than a man should have." Some of this work was published in Proceedings of the Electron Microscope Society of America (EMSA).

Upon graduation from the University of Michigan with a BS in Science Engineering, Allard began his doctoral research at Michigan. In 1969 he received notice that he was being drafted into the military. Fortunately, Allard had passed his qualifying exams, and Michigan awarded him a master's degree in metallurgical engineering. The draft board also recognized his expertise, so he was allowed to fulfill his service working on classified projects at the ORGDP involving gas reactions for uranium isotope separation processes. After completing his service requirement Allard returned to the University of Michigan to complete his doctoral research, which he did in 1981. Connections made during his service would lead him back to Oak Ridge in 1986 for a position in the new High Temperature Materials Laboratory.

In 2006 Dr. Allard was thinking about a new experimental thrust for his newly installed JEOL 2200FS aberration-corrected microscope, and his thoughts returned to in situ gas reactions. Serendipitously, a week after proposing the idea to his manager, he received a call from John Damiano and David Nackashi of Protochips who were interested in advancing the utility of their microelectromechanical systems (MEMS)-based heating devices (E-chips) for in situ electron microscopy studies. Unable to contain his excitement, Dr. Allard declared, "Boy have you come to the right guy!" The feeling was instantly mutual, as his collaborators appreciated his ability to boldly push boundaries without recklessness. Allard and Bigelow began a lasting collaboration with the team at Protochips. Bigelow was responsible for the initial holder design and construction [1].

With the aim of building a closed-cell system that would be universal for all microscopes, the team began with a 3-chip configuration with the middle chip serving as the heating element. They quickly learned this could be reduced to a more efficient and slimmer 2-chip design and still retain the closed nature, where the top chip acts both as the heater and seals the environment [2]. After several iterations, the holder permits tilt up to 18 degrees to allow $\mathrm{x}$-ray collection and thereby "operando" in situ experiments. It is impressive to think of the strides made by Dr. Allard and his colleagues and even more so to think of the improvements since the earliest experiments in 1965. It speaks to Dr. Allard's willingness to experiment and test new ideas, that in under a decade the initial simple heating holder evolved into a refined design with high-tilt capabilities for operando experiments.

Dr. Allard reflected on the improvements, and speaking of the first iteration, "We took enamel-coated copper wires and scraped the enamel off the ends to contact the gold electrodes on the MEMS E-chip. It was early on just serendipity that we were able to assemble it, seal the cell, heat it, and maintain the vacuum of the column." Reflecting on the system built for the experiments in the 1960s, he noted about how vibrations from the motor drive of the camera limited the magnification they could use and, ultimately, the resolution to $\sim 20 \AA$ on a good day.

In the beginning stages of his EM career with Prof. Bigelow, despite all of the limitations-tungsten filaments burning out every few days, a bulky noise-inducing camera teetering on the edge of vacuum requirements-Dr. Allard tinkered, built, and pioneered the world of microscopy into the dawn of in situ ultrastructural research. Now, in the later years of his career, with old and new collaborators, he has brought us into the age of gas cell in situ. With these innovations we are now able to explore those important questions where before-and-after imaging won't suffice. Dr. Allard credits luck for his experiences and collaborations in the development of the in situ gas cell. However, it is perhaps more accurate to say his successes are a result of his willingness to walk through the figurative and literal open doors of electron microscopy.

\section{References}

[1] Allard et al., Microscopy Res \& Tech 72(3) (2009) 208-15.

[2] Allard et al., Microsc Microanal 18(2) (2012) 655-56.

\section{Add Micro XRF to your SEM}

-...... Accommodates all SEM manufacturers

-.... Uses your existing EDS system to acquire

-.... Better sensitives for energies $>2 \mathrm{keV}$

-... Improved signal to noise ratio $(\mathrm{p} / \mathrm{b})$

-... Combine EDS with XRF analysis

-.... Full quantitative software

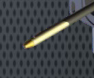

- Low ppm trace detection
10, 20,40, Micron

Polycapillary
EDS

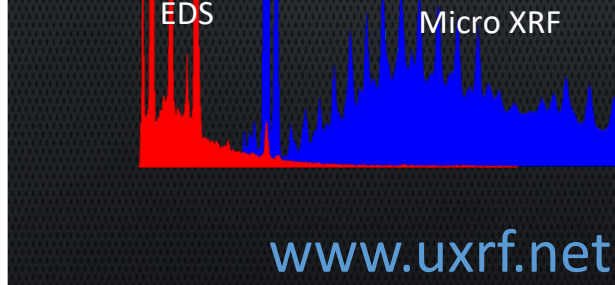

